\title{
Transition Metal Schiff Base Complexes Synthesis, Spectral Examination and used as a Catalyst in the Oxidation of Alcohols and C-C Coupling Reactions
}

\author{
Arunachalam. S, Selva Kumar. B, Arunpandian. M
}

\begin{abstract}
In this correspondence, it reveals the formation of Co (II) and $\mathrm{Cu}$ (II) complexes consists of a Schiff base ligand having the four donar destinations $2 \mathrm{NO}$. Co(II) and $\mathrm{Cu}(\mathrm{II})$ complexes were made ready by the response of $1: 1$ proportion of the $\mathrm{MCl}_{2} .6 \mathrm{H}_{2} \mathrm{O}(\mathrm{M}=\mathrm{Co} / \mathrm{Cu})$ with a Schiff base ligand prepared by the response of 2-hydroxynaphthaldehyde with orthophenylene diamine in ethanolic medium having the stoichimetric proportion of 2:1. The purged and arranged complexes were analytically explored. Catalytic efficacy was assessed for oxidation of alcohols and $C$-C coupling responses.
\end{abstract}

Keywords: Cu (II), Co (II), Schiff base, complexes, oxidation of alcohols, $C$-C coupling

\section{INTRODUCTION}

The reaction of an amine with an aldehyde or a ketone in fitting conditions produces Schiff base ligands. Basically, Schiff base can be consolidated by the substitution of a carbonyl social affair with an imine or azomethine in the nitrogen straightforward of an aldehyde or ketone. Schiff base can interface with by far most of the metal particles to convey diverse edifices [1-3]. Schiff base ligands have a kind of physio-compound properties. Most Schiff base ligands have an imperative occupation in various reactions in light of their high synergist development that extension the yield and selectivity. When all is said in done, the reactant use of Schiff assembles as metal complexes depends as for the system that has been used for blend and thermo-strength of these ligands[4]. Schiff base structures of assortment of metallic particles work as powerful catalyst in homogeneous and heterogeneous reactions and their development differentiates according to the metallic particles, kind of ligands and coordination modes[5,6]. The metal buildings of Schiff bases have been used as stimuli in the midst of the latest decades in various responses, additionally, oxidation of natural aggravates that has pulled in a colossal thought in the field of academic and present day examination [7]. Metal Schiff-base structures have been used as catalyst for the assortment of oxidation of alcohols and C-C coupling reactions [8-12].

\section{MATERIALS AND METHODS}

\section{A. Materials and characterization}

Every one of the reagents was synthetically unadulterated. Every one of the solvents was newly refined before use. Microanalyses were performed with a VarioEL III Elemntal analyzer at the Department of Chemistry, Bharathiar University, India. Infrared Spectra of the complexes were recorded in $\mathrm{KBr}$ pellets on utilizing Shimadzu/Nicolet instrument in the range $4000-400 \mathrm{~cm}-1$. Electronic Spectra of the complexes have been recorded in methanol utilizing Systronics 119 Spectrophotometer in the range 260-400 nm. Cyclic Voltammetric analysis were done with EG and G-PARC M273 display cyclic voltammeter in dichloromethane utilizing smooth Carbon working electrode. Platinum foil and Silver wire were utilized as counter and reference anodes. Tetrabutyl ammonium tetrafluoroborate was utilized as supporting electrolyte. The EPR spectral information of the $[\mathrm{Cu}(\mathrm{L})]$ complex was investigated in Pondichery college and DPPH was utilized as g marker. The melting point was recorded with Raaga device and is uncorrected. The tetradentate Schiff base ligand were readied (Scheme 1) by announced protocol[13].

Revised Manuscript Received on December 09, 2019.

* Correspondence Author

S. Arunachalam*, Nanomaterials Laboratory, Department of Chemistry, International Research Centre, Kalasalingam Academy of Research and Education (Deemed to be University), Krishnankoil - 626126, India. Email: drarunachalam.s@gmail.com

K. Selvakumar, Nanomaterials Laboratory, Department of Chemistry, International Research Centre, Kalasalingam Academy of Research and Education (Deemed to be University), Krishnankoil - 626126, India. Email: selvachemistk@gmail.com

M. Arunpandian, Nanomaterials Laboratory, Department of Chemistry, International Research Centre, Kalasalingam Academy of Research and Education (Deemed to be University), Krishnankoil - 626126, India. Email: arunpandiantt126@gmail.com 

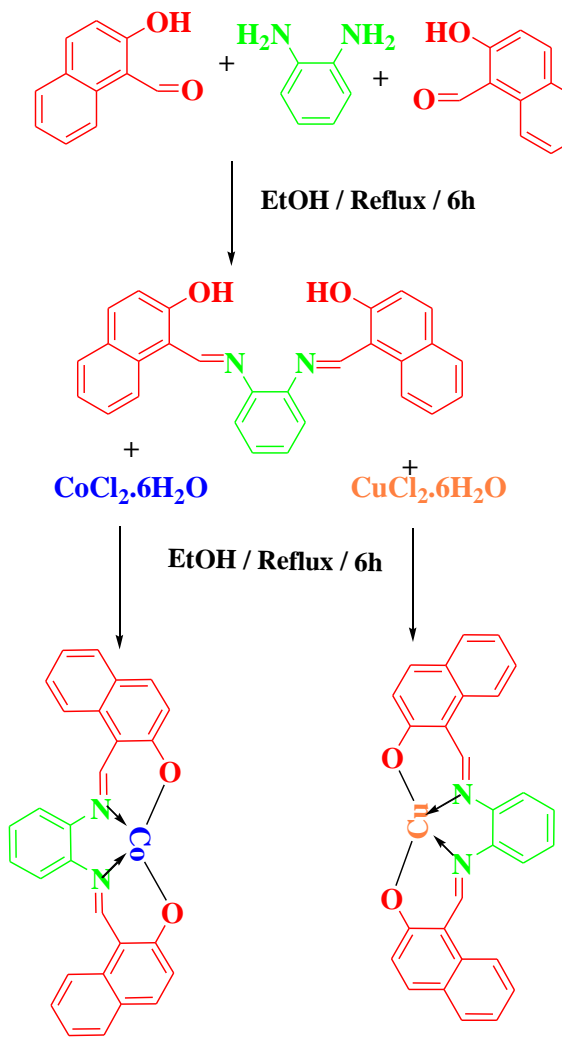

Scheme 1. Synthesis of $\mathrm{Co}(\mathrm{II}) / \mathrm{Cu}(\mathrm{II})$ Tetradentate Scihff base complexes

\section{B. Preparation of complexes $[\mathrm{Cu}(\mathrm{L})]$ and $[\mathrm{Co}(\mathrm{L})]$}

To a solution of $\mathrm{CuCl}_{2} .6 \mathrm{H}_{2} \mathrm{O} \quad(0.25 \mathrm{~g}$; $0.1 \mathrm{mmol}) / \mathrm{CoCl}_{2} .6 \mathrm{H}_{2} \mathrm{O}(0.24 \mathrm{~g} ; 0.1 \mathrm{mmol})$ in ethanol $\left(20 \mathrm{~cm}^{3}\right)$, the Schiff base ligand H2L $(0.424 \mathrm{~g} ; 0.1 \mathrm{mmol})$ was included (molar proportion of metal salt: Schiff base is $1: 1)$. The blend was warmed under reflux for $5 \mathrm{hrs}$ the subsequent mixture was concentrated to around $10 \mathrm{~cm}^{3}$ and the item acquired on cooling was washed with petroleum ether $\left(60-80^{\circ} \mathrm{C}\right)$ and recrystallised from $\mathrm{CH}_{2} \mathrm{Cl}_{2}$ /petroleum ether and dried under vacuum (Scheme 1).

\section{Catalytic Acivity}

The catalytic oxidation and the $\mathrm{C}-\mathrm{C}$ coupling reactions were done by using the reported literatures [14], [15].

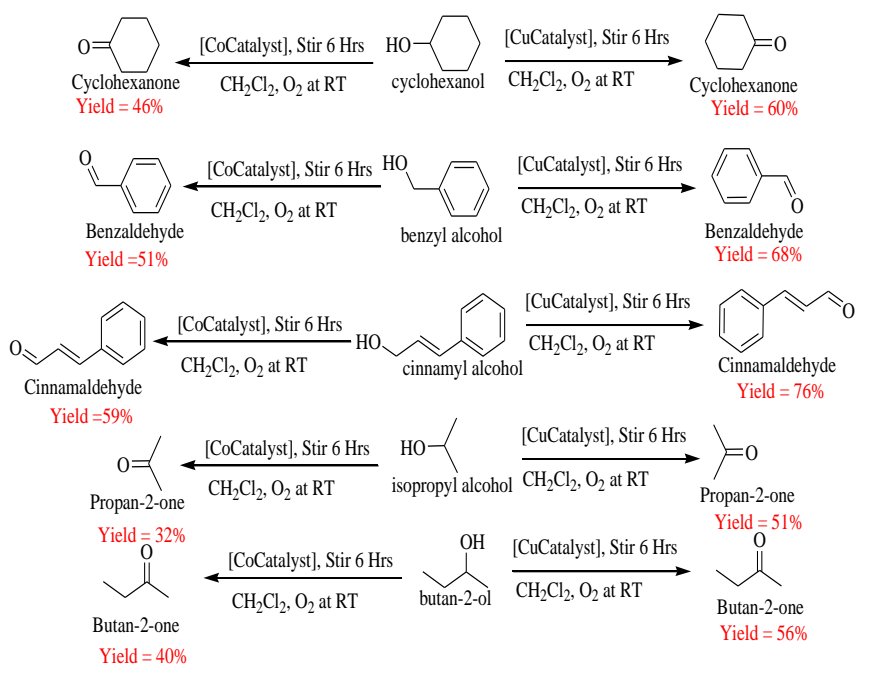

Scheme 2. Oxidation of Alcohols by $\mathrm{Co}$ (II) / $\mathrm{Cu}$ (II) tetradentate Schiff base complexes

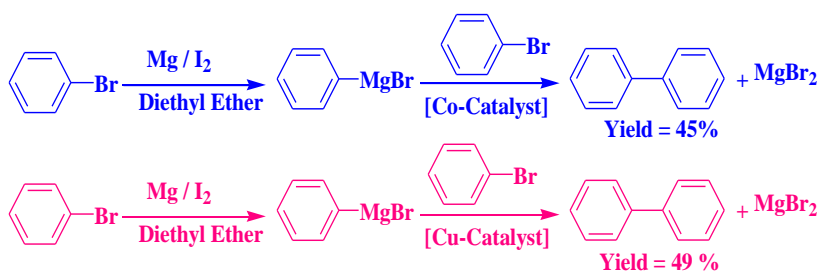

Scheme 3. C-C coupling by $\mathrm{Co}$ (II) / Cu(II) tetradentate Schiff base complexes

\section{RESULTS AND DISCUSSIONS}

\section{A. Preparation of Schiff base complexes}

Stable Co(II) / Cu(II) Schiff base complexes of the general formula $[\mathrm{Co}(\mathrm{L})]$ and $[\mathrm{Cu}(\mathrm{L})](\mathrm{L}=$ dianion tetradentate Schiff base) have been prepared by reacting $\mathrm{CoCl}_{2} \cdot 6 \mathrm{H}_{2} \mathrm{O}$ and $\mathrm{CuCl}_{2} \cdot 6 \mathrm{H}_{2} \mathrm{O}$ with the respective Schiff bases in a 1:1 molar ratio in ethanol (Scheme 1). All the complexes are soluble in most of the common organic solvents. Their purity was checked by TLC on silica gel. The analytical data obtained for the new complexes agree well with the proposed molecular formulae (Table 1). In all of the above reactions, the Schiff bases behave as binegative tetradentate ligands.

Table 1. Analytical data of Schiff base and its complexes

\begin{tabular}{|l|l|l|l|}
\hline $\begin{array}{l}\text { Physical } \\
\text { properties / } \\
\text { Compounds }\end{array}$ & $\mathrm{H}_{2} \mathbf{L}$ & {$[\mathrm{CoL}]$} & {$[\mathrm{CuL}]$} \\
\hline Color & Orange & Brown & Brown \\
\hline $\begin{array}{l}\text { Melting } \\
\text { Point }{ }^{\circ} \mathrm{C}\end{array}$ & $185^{\circ} \mathrm{C}$ & $>250^{\circ} \mathrm{C}$ & $>250^{\circ} \mathrm{C}$ \\
\hline $\begin{array}{l}\text { Molecular } \\
\text { formula }\end{array}$ & $\mathrm{C}_{28} \mathrm{H}_{20} \mathrm{~N}_{2} \mathrm{O}_{2}$ & $\mathrm{C}_{28} \mathrm{H}_{18} \mathrm{CoN}_{2} \mathrm{O}_{2}$ & $\mathrm{C}_{28} \mathrm{H}_{18} \mathrm{CuN}_{2} \mathrm{O}_{2}$ \\
\hline $\begin{array}{l}\text { Molecular } \\
\text { weight }\end{array}$ & 416.47 & 473.39 & 478.00 \\
\hline $\begin{array}{l}\text { Elemental } \\
\text { Analysis }\end{array}$ & Found (calculated)(\%) & \\
\hline $\mathrm{C}$ & $80.75(79.89)$ & $71.04(70.98)$ & $70.36(70.25)$ \\
\hline $\mathrm{H}$ & $4.84(7.78)$ & $3.83(3.81)$ & $3.80(3.84)$ \\
\hline $\mathrm{N}$ & $6.73(6.75)$ & $5.92(5.9)$ & $5.86(5.1)$ \\
\hline
\end{tabular}

\section{B. IR spectra}

The IR spectral assignments are given in the Table 2. The IR spectra of the free Schiff base ligand have been contrasted with their complexes all together with discover the method of coordination of the ligand to the metal ion. The trademark IR ingestion frequencies found for the free Schiff base ligand will be marginally moved if some contributor particles of the ligand are connected to the metal in the edifices. Subsequently, by inspecting the IR spectra of the buildings and that of the free ligand it is conceivable to get data about the connection of the ligand to the metal particle in the complex.

The free Schiff base ligand demonstrated an extremely solid ingestion at $1614 \mathrm{~cm}-1$ in its IR spectra, which is normal for the azomethine $v(\mathrm{C}=\mathrm{N})$ gathering. In the Schiff base complexes, this recurrence is moved to the area around 1608-1609 cm-1 demonstrating the coordination of the Schiff base through the azomethine nitrogen moiety $[16,17]$. A solid band saw at $1321 \mathrm{~cm}-1$ area in the free Schiff base because of phenolic $\mathrm{C}-\mathrm{O}$, increments on complexation by $45 \mathrm{~cm}-1$ showing the other 
coordination site is through the phenolic oxygen[3]. In the ligand a wide band saw at $3413 \mathrm{~cm}-1$ comparing to $v(\mathrm{OH})$ vanished totally in the edifices showing deprotonation before the coordination through the oxygen atom.

\section{Electronic spectroscopy}

The electronic spectra of the complexes were recorded in methanol. The electronic spectral information is given in Table. 2 and the delegate specrtrum is shown in Fig.1. The electronic range indicated five to seven groups in the area of $260-600 \mathrm{~nm}$. The groups at $262-399 \mathrm{~nm}$. Relates to LMCT $(\mathrm{s} \rightarrow \mathrm{d})$ progress and the shoulder at $490 \mathrm{~nm}$ compares to unsanctioned $\mathrm{d}-\mathrm{d}$ transition. The extra shoulder at the locale around $581 \mathrm{~nm}$ compares to $\mathrm{A}_{1 \mathrm{~g}} \rightarrow \mathrm{A}_{2 \mathrm{~g}}$ change of a square planar complex[18].

Table 2. FT- IR and Electronic spectral data of Schiff base complexes

\begin{tabular}{lllll}
\hline Complex & \multicolumn{2}{l}{ FT-IR $\left(\mathbf{c m}^{-1}\right)$} & \multicolumn{2}{l}{$\mathbf{U V - V I S ~} \boldsymbol{\lambda}_{\max }$} \\
\cline { 2 - 4 } & $\mathbf{v}_{\mathbf{O H}}$ & $\mathbf{v}_{\mathbf{C}=\mathbf{N}}$ & $\mathbf{v}_{\mathbf{C}-\mathbf{O}^{-}}$ & \\
\hline $\mathrm{H}_{2} \mathrm{~L}$ & 3413 & 1614 & 1321 & $262,281,339$, \\
{$[\mathrm{CoL}]$} & - & 1607 & 1365 & $490,512,581$ \\
{$[\mathrm{CuL}]$} & - & 1608 & 1365 & \\
\hline
\end{tabular}

\section{EPR Spectra}

The EPR Spectra of powered samples were recorded at room temperature (Fig. 1). The EPR spectra of the complex $[\mathrm{Cu}(\mathrm{L})]$ are found to be isotropic consisting of one ' $\mathrm{g}$ ' value (2.11) with no appearance of hyperfine structure characteristic of regular geometry. The broad spectral signal could be attributed to super exchange interaction between copper centers in the solid state[19].

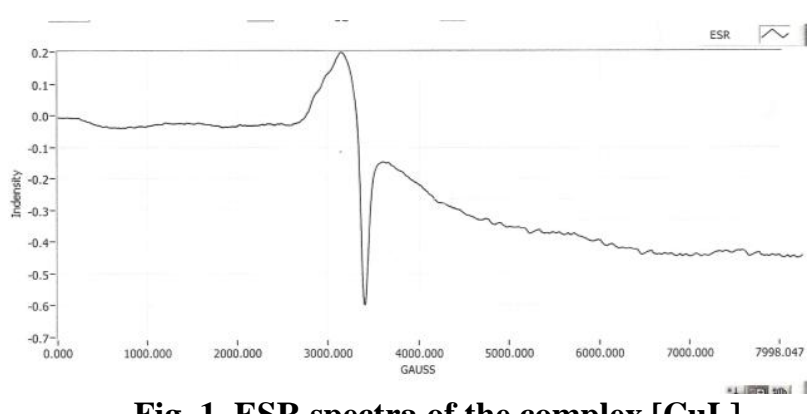

Fig. 1. ESR spectra of the complex [CuL]

\section{E. Cyclic voltametric studies}

Cyclic voltametric studies (Table 3 ) have been done for the previously mentioned complexes in dichloromethane utilizing smooth carbon working cathode at output rate $100 \mathrm{mV} / \mathrm{s}$. The supporting electrolyte utilized was $0.01 \mathrm{M}$ [NBu4]BF4 in dichloromethane arrangement. The arrangement was degassed with the progression of nitrogen gas before filtering. Every one of the possibilities were referenced to $\mathrm{Ag} / \mathrm{AgCl}$ anode. The redox possibilities of the edifices were described by all around characterized waves. The cyclic voltametric information are given the Table 2 . The Cobalt complex $[\mathrm{Co}(\mathrm{L})]$ indicated just a semi reversible oxidation from Co(II) to Co(III) at $0.499 \mathrm{~V}$ and The complex $[\mathrm{Cu}(\mathrm{L})]$ demonstrated just a semi reversible decrease of $\mathrm{Cu}(\mathrm{II})$ to $\mathrm{Cu}(\mathrm{I})$ at $0.456 \mathrm{~V}$. The purpose behind demonstrating just oxidation potential on account of cobalt complex is

because of the brief oxidation condition of metals[18,19] or oxidative humiliation of the ligands[20].

Table 3. FT- IR, Electronic spectral and Electrochemical data of Schiff base

\begin{tabular}{|l|l|l|l|l|}
\hline \multirow{2}{*}{ Complex } & \multicolumn{4}{|l|}{ Electrochemistry $\left(\mathbf{M}^{\text {II }}-\mathbf{M}^{\text {III }}\right)$} \\
\cline { 2 - 5 } & $\mathbf{E}_{\mathbf{p a}}$ & $\mathbf{E}_{\mathbf{p c}}$ & $\mathbf{E}_{\mathbf{1 / 2}}$ & $\Delta \mathbf{E}_{\mathbf{p}}$ \\
\hline $\mathrm{H}_{2} \mathrm{~L}$ & - & -0.144 & 0.106 & 499 \\
\hline$[\mathrm{CoL}]$ & 0.355 & -0.539 & -0.311 & 456 \\
\hline$[\mathrm{CuL}]$ & -0.83 & \multicolumn{4}{|l}{} \\
\hline
\end{tabular}

\section{F. Catalyic Activities \\ Catalytic oxidation}

The oxidation of benzyl alcohol, cyclohexanol, cinnamyl alcohol, isopropyl alcohol and butan-2-ol was done with the diverse metal complexes as catalyst utilizing oxygen molecule as co-oxidant at encompassing temperature in dichloromethane (Scheme 2). For no situation was there any recognizable oxidation of alcohols within the sight of oxygen molecule alone without the metal complexes. Benzaldehyde was framed from benzyl alcohol, cyclohexanol was changed over into cyclohexanone, cinnamyl alcohol was changed over cinnamaldehyde and butan-2-ol was changed over to butan-2-al after $3 \mathrm{~h}$ of mixing at room temperature. The aldehyde/ketone framed were evaluated as their 2,4-dinitrophenylhydrazone subordinates. All the orchestrated $\mathrm{Co}$ and $\mathrm{Cu}$ complexes were found to catalyze the oxidation of alcohols to aldehydes/ketones, yet the yields and the turnover were found to fluctuate with various impetuses. The generally higher item yield got for the oxidation of benzyl liquor than for cyclohexanol was because of the way that the $\alpha-\mathrm{CH}$ moiety of benzyl alcohol is more acidic than that of cyclohexanol[15]. The moderately higher item yield got for the oxidation of cinamyl alcohol than benzyl alcohol is because of the nearness of unsaturated aliphatic gathering in the cinnamyl alcohol[16].

\section{G. Aryl-aryl coupling}

The new complexes have additionally been utilized as a catalsyt for aryl-aryl coupling responses (Scheme 3 ). The framework picked for the examination is the coupling of phenylmagnesium bromide with bromobenzene to give biphenyl as the item. Bromobenzene was first changed over into the comparing Grignard reagent. At that point bromobenzene pursued by the unpredictable picked for examinations was added to the above reagent and the blend was warmed under reflux for $6 \mathrm{~h}$. After workup, the blend yielded biphenyl. Just an extremely modest quantity of biphenyl was framed when the response was done without the catalyst. This is an inconsequential sum contrasted with the yields of biphenyl got from the response catalyzed by $\mathrm{Co} / \mathrm{Cu}$ comlpexes [21].

\section{CONCLUSION}

$\mathrm{Cu}(\mathrm{II})$ and $\mathrm{Co}(\mathrm{II})$ complexes got from tetradentate Schiff bases were combined and portrayed by essential and spectroscopic techniques. The otherworldly examination affirms the arrangement of 
bonds between the ligands and copper and cobalt antecedents. The outcomes outline that the complexes are chemically dynamic demonstrating diverse scope of possibilities in catalytic oxidation of alcohols and $\mathrm{C}-\mathrm{C}$ coupling responses. Generally discoveries of this report bolster the view that these complexes can be a promising wellspring of potential catalysts.

\section{References}

1. A.H. Mirza, M.H.S. A. Hamid, S. Aripin, M.R. Karim, M. Ali Arifuzzaman, M.A. Ali, P.V. Bernhardt, Polyhedron, 2014, 74, 16-23.

2. A.H. Mirza, A.M. Akbar, P.V. Bernhardt, I. Asri, Polyhedron, 2014, 81, 723-727.

3. Y.P. Tian, Y.C.Y. Duan, C.Y. Zhao and X.Z. You, Inorg. Chem, 1997, 36, 1247-1252.

4. K.C. Gupta and A. K. Sutar, Coord. Chem. Rev., 2008, 252, $1420-1450$.

5. M. P. de Almeida, L. M. D. R. S. Martins, S. A. C. Carabineiro, T. Lauterbach, F. Rominger,S. K. Hashmi, A. J. L. Pombeiro and J. L. Figueiredo, Catal. Sci. Technol, 2013, 3,3056-3069.

6. Z.H. Liu, C.Y. Duan, J. Hu and X.Z. You, Inorg. Chem., 1999, 38, $1719-1724$.

7. A. M. Abu-Dief and I. M. A. Mohamed, Beni-Suef University Journal of Basic and Applied Sciences, 2015, 4, 119-133.

8. E.C. Niederhoffer, J.H. Timmons, A.E. Martell, Chem. Rev., 1984, 84, 137.

9. S. Yamada, Coord. Chem. Rev., 1999, 191, 537.

10. N.J. Henson, P.J. Hay, A. Redondo, Inorg. Chem., 1999, 38, 1618.

11. A.E. Martell, D.T. Sawyer, Oxygen Complexes and Oxygen Activation by Transition Metals, Plenum Press, New York, 1988.

12. C. Bianchini, R.W. Zoeliner, Adv. Inorg. Chem., 1997, 44, 263.

13. M. L. Illingoworth and A. L. Rheingold, Inorg. Chem ., 1987, 26, 4312.

14. S. Arunachalam, N. Padma Priya and H. Shahul Meeran, J. Ind. Chem. Soc., 2014, 91, 56

15. S. Arunachalam, N. Padma Priya, K. Boopathi, C. Jayabalakrishnan and V. Chinnusamy, Appl. Organomet. Chem., 2010, 24, 491-498

16. S. Arunachalam, N. Padma Priya, C. Saravanakumar, C. Jayabalakrishnan and V. Chinnusamy, J. Coord. Chem.,2010, 63, 1795-1806.

17. S. Manivannan, A. Manimaran, S. Arunachalam, C. Jayabalakrishnan and V. Chinnusamy. J. Ind. Chem. Soc., 2008, 85, 988.

18. V. Atre, G.V. Reddy, L. N. Sharadha and M. C. Gonarka, Ind. J. Chem., 1982, 21A, 935.

19. S. Chandra, L.K. Gupta, Spectrochim. Acta Part A, 2004, 60, 1563-1571.

20. A. M. Bond, R. Cotton and D. R. Manu, Inorg. Chem., 1990, 29, 4665

21. R. Madaselvi, N. Padma Priya, M. Jayaraj, C. Arun Paul, K. Kalaivani, S. Arunachalam, Asian Journal of Chemistry.,2016, 28, 1682-1686.

\section{AUTHORS PROFILE}

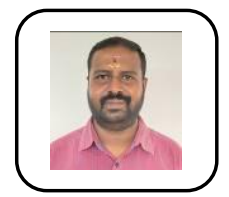

Dr. S. Arunachalam is Assistant Professor in Department of Chemistry, International Research Centre, Kalasalingam Academy of Research and Education (Deemed to be University), Krishnankoil, India. His area of Research is Inorganic and Bio-inorganic chemistry, Photocatalysis, etc.

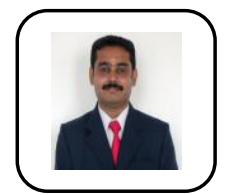

Dr. B. Selvakumar, Professor and head in Departmen of Physics, International Research Centre, Kalasalingam Academy of Research and Education (Deemed to be University), Krishnankoil, India. He is working in the teaching and Research field in 16 years. He is well known in the specialization of Solar energy utilization.

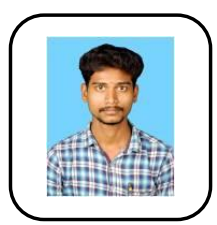

M. Arunpandian is a research scholar at Nanomateria Laboratory, Department of Chemistry, International Research Centre, Kalasalingam Academy of Research and Education (Deemed to be University), Krishnankoil, India. He is working in the area materials Characterization, waste water purification and Photocatalysis. 